\title{
Correlative Variation of The Essential Amino Acids
}

\author{
Mazurkin P M* \\ Professor, Russia \\ Received: 此 November 04, 2018; Published: 眥 November 14, 2018 \\ *Corresponding author: Mazurkin P M, Professor, Russia
}

\begin{abstract}
On the example of the table of contents of eight essential amino acids in 22 products, the methodology of factor analysis and determination of the coefficient of correlation variation, calculated as the ratio of the sum of the correlation coefficients of stable laws and laws of binary relations between amino acids to the product of the number of amino acids as influencing variables and as dependent indicators. It is shown that this evaluation criterion depends on the composition of the products and the set of amino acids considered. Therefore, it is proposed to make a more complete table considering the set of objects, which considers the content of all 20 amino acids. The law of binary relations between amino acids is the sum of the exponential law and the biotechnical law of stress excitation in the product. By correlation coefficients of individual binary relations, the ratings of amino acids as influencing variables and as dependent indicators are performed. The correlation matrix of super strong bonds of essential amino acids with correlation coefficients of more than 0.99 is considered, in part of which the graphs are given. By the nature of behavior, it is proposed to classify the binary relationships between amino acids into positive, neutral and negative. Separately, the method of rating products. The equations and graphs of rank distributions of the content of essential amino acids in products are given. The rating of essential amino acids by dispersion of residues from the equations of binary relations and rank distributions is given.
\end{abstract}

Keywords: Amino Acids; Products; Factor Analysis; Regularities; Correlation Coefficients; Coefficient of A Correlative Variation

\section{Introduction}

Under the expression correlative variation Charles Darwin understands that the whole organization is internally connected during growth and development, and when weak variations occur in one part and are cumulated by natural selection, the other parts are modified. Modifications in the structure recognized by taxonomists for a very important, can depend solely on the laws of variation and correlation [1]. For example, Phyto enosis [2] has at least three fundamental properties: first, the correlative variation in the values of parameters in time and space; second, the correlation depends on the genotypic properties of the plant species; third, the variation is due to phenotypic properties, as well as the cycles of solar activity [3], the rotation of the moon around the Earth and our planet around itself [4].

In accordance with the correlative variation of Charles Darwin, during the growth and development of the body, significant changes in the initial age will lead to changes in the structure and in the adult creature. Therefore, people, taking, and thereby enhancing some feature of, almost, probably, unintentionally modifying other parts of the body based on the mysterious laws of correlation [1]. Any non-investigative variation is insignificant for us. But the number and variety of hereditary deviations in the structure, both minor and very important in physiological terms, is infinite. All things are things, properties and relations [5], and in the bios relations control things and change their structures. The purpose of the article is to show the laws and regularities of the correlative variation of the content of eight essential amino acids in a set of 22 products.

\section{The Concept of Correlative Variation}

Variability [1] is usually associated with the living conditions that the species has been subjected to for several successive generations. In General, according to Darwin, there are two factors: the nature of the body (most important factor) and the properties of existing conditions [1]. Thus, we adopted the basic hypothesis that typing, and the classification has no effect on biotech based on mastery of life laws. Therefore, the variation (the set of deviations from the Darwin correlation) depends on the human factor, i.e. on the quality of measurements of soil properties and plants $[4,6]$. Soil according to V.V. Dokuchaev [7] is a living organism. Therefore, the principle of Darwin's correlative variation should provide high adequacy of the revealed regularities [6]. Similarly, a priori we will consider experiments with essential amino acids [8] to measure their concentration in different types of products for humans and animals highly correlative. 
From the concept of correlative variation of Charles Darwin, which was not understood by mathematicians and was not developed by biologists, it clearly follows that in other conditions of the habitat other combinations of values of factors may be stronger (Darwin calls factors hereditary deviations). Therefore, weak factor connections may be stronger for other combinations of the studied objects. As a result, there is a mathematical tool [912] (identification method) for comparison of different natural and artificial (technical) objects [13]. The coefficient of correlative variation is considered for many factors of the physical object of study, that is, biological, chemical, technological, socio-economic, etc. It is equal to the ratio of the total sum of the correlation coefficients to the square of the number of factors for the complete table model (or to the product of the number of factors and). The type of the system under study does not affect this criterion, and the correlation variation depends entirely on the internal properties of the system under study. The coefficient of correlative variation is calculated by the formula

$$
k=\sum \sum r / N^{2} \text { or } k=\sum \sum r /\left(N_{x} . N_{y}\right)
$$

where

$K$ - the coefficient of correlative variation of the set of factors or parameters characterizing the system under study,

Table 1: The content of essential amino acids in products [1] (grams per 100 grams of product), We have included in the list of products №22 «Shiitake mushrooms».

\begin{tabular}{|c|c|c|c|c|c|c|c|c|c|c|}
\hline No. & Product & Leucine & Isoleucine & Histidine & Tyrosine & Glycine & Lysine & Valine & Methionine & Pheny-lalanine \\
\hline 1 & Milk for women & 0.108 & 0.062 & 0.028 & 0.060 & 0.042 & 0.082 & 0.072 & 0.022 & 0.056 \\
\hline 2 & Cow's milk & 0.278 & 0.182 & 0.081 & 0.119 & 0.030 & 0.218 & 0.189 & 0.068 & 0.136 \\
\hline 3 & Kefir & 0.263 & 0.173 & 0.075 & 0.112 & 0.056 & 0.209 & 0.183 & 0.063 & 0.138 \\
\hline 4 & Curd & 0.924 & 0.548 & 0.306 & 0.456 & 0.184 & 0.725 & 0.695 & 0.263 & 0.491 \\
\hline 5 & Chicken egg & 1.130 & 0.830 & 0.294 & 0.515 & 0.370 & 0.883 & 0.895 & 0.378 & 0.732 \\
\hline 6 & Beef meat & 1.730 & 1.060 & 0.805 & 0.596 & 1.447 & 2.009 & 1.156 & 0.528 & 0.789 \\
\hline 7 & Chicken meat & 1.620 & 1.117 & 0.697 & 0.660 & 1.519 & 1.975 & 1.024 & 0.494 & 0.932 \\
\hline 8 & Beef liver & 1.543 & 0.800 & 0.439 & 0.470 & 0.903 & 1.295 & 0.987 & 0.345 & 0.845 \\
\hline 9 & Cod & 1.222 & 0.879 & 0.540 & 0.439 & 0.525 & 1.551 & 0.929 & 0.488 & 0.651 \\
\hline 10 & Rice grits & 1.008 & 0.369 & 0.135 & 0.176 & 0.630 & 0.142 & 0.425 & 0.223 & 0.313 \\
\hline 11 & Semolina & 0.364 & 0.258 & 0.186 & 0.158 & 0.263 & 0.320 & 0.386 & 0.103 & 0.399 \\
\hline 12 & Buckwheat & 0.702 & 0.301 & 0.203 & 0.160 & 0.796 & 0.431 & 0.343 & 0.183 & 0.395 \\
\hline 13 & Oatmeal & 0.672 & 0.302 & 0.137 & 0.234 & 0.453 & 0.384 & 0.384 & 0.198 & 0.363 \\
\hline 14 & Millet grits & 1.040 & 0.244 & 0.137 & 0.226 & 0.220 & 0.226 & 0.333 & 0.207 & 0.480 \\
\hline 15 & Pearl barley & 0.584 & 0.258 & 0.152 & 0.148 & 0.308 & 0.286 & 0.313 & 0.173 & 0.331 \\
\hline 16 & Pea & 1.204 & 0.780 & 0.395 & 0.227 & 0.48 & 0.984 & 0.804 & 0.160 & 0.763 \\
\hline 17 & Wheat flour & 0.567 & 0.290 & 0.096 & 0.149 & 0.149 & 0.120 & 0.387 & 0.108 & 0.322 \\
\hline 18 & Pasta & 0.690 & 0.380 & 0.133 & 0.253 & 0.215 & 0.139 & 0.412 & 0.120 & 0.488 \\
\hline 19 & Rye bread & 0.275 & 0.146 & 0.118 & 0.293 & 0.217 & 0.132 & 0.062 & 0.062 & 0.278 \\
\hline 20 & Wheat bread & 0.550 & 0.250 & 0.106 & 0.162 & 0.264 & 0.103 & 0.286 & 0.088 & 0.330 \\
\hline 21 & Cookie & 0.357 & 0.171 & 0.247 & 0.088 & 0.172 & 0.080 & 0.054 & 0.054 & 0.334 \\
\hline 22 & Shiitake mushrooms & 7.000 & 4.400 & 1.800 & 3.500 & - & 3.500 & 5.200 & 1.800 & 5.300 \\
\hline
\end{tabular}




\section{Rating of Influencing and Dependent Factors}

To determine the coefficient of correlative variation of nine amino acids among 22 types of products it is necessary to conduct a factor analysis [9]. Due to the absence of a measured value of glycine content in one cell of Table 1 in the row Shiitaki mushrooms, factor analysis was first carried out [9, pp. 82-83, table. 3.30] nine factors and 21 products. The coefficient of correlative variation was equal to 0.9985 . All binary $92-9=72$ relations are characterized by the exponential law. Table 2 shows the correlation matrix of binary relationships and the rating of eight factors excluding glycine for 22 products according to Table 1.

Table 2: Correlation matrix of factor analysis without glycine and rating of factors in identification by the exponential law.

\begin{tabular}{|c|c|c|c|c|c|c|c|c|c|c|}
\hline \multirow{2}{*}{$\begin{array}{c}\text { Influencing } \\
\text { Factors } \\
\text { (characteristic } \\
x \text { ) }\end{array}$} & \multicolumn{8}{|c|}{ Dependent Factors ( $y$ indicators) } & \multirow[b]{2}{*}{ Sum $\Sigma r$} & \multirow[b]{2}{*}{ Place $I_{x}$} \\
\hline & Leucine & Isoleucine & Histidine & Tyrosine & Lysine & Valine & Methionine & Phenylalanine & & \\
\hline Leucine & 1 & 0.9910 & 0.9550 & 0.9907 & 0.8927 & 0.9937 & 0.9842 & 0.9940 & 7.8013 & 4 \\
\hline Isoleucine & 0.9896 & 1 & 0.9738 & 0.9918 & 0.9306 & 0.9972 & 0.9871 & 0.9909 & 7.8610 & 1 \\
\hline Histidine & 0.9603 & 0.9791 & 1 & 0.9725 & 0.9692 & 0.9716 & 0.9722 & 0.9630 & 7.7879 & 5 \\
\hline Tyrosine & 0.9838 & 0.9878 & 0.9484 & 1 & 0.8863 & 0.9889 & 0.9822 & 0.9910 & 7.7684 & 6 \\
\hline Lysine & 0.9163 & 0.9518 & 0.9726 & 0.9575 & 1 & 0.9448 & 0.9449 & 0.9387 & 7.6266 & 8 \\
\hline Valine & 0.9918 & 0.9969 & 0.9597 & 0.9922 & 0.9145 & 1 & 0.9860 & 0.9924 & 7.8335 & 2 \\
\hline Methionine & 0.9840 & 0.9888 & 0.9668 & 0.9898 & 0.9298 & 0.9888 & 1 & 0.9797 & 7.8277 & 3 \\
\hline Phenylalanine & 0.9910 & 0.9884 & 0.9446 & 0.9921 & 0.8664 & 0.9907 & 0.9708 & 1 & 7.7440 & 7 \\
\hline Sum $\Sigma r$ & 7.8168 & 7.8838 & 7.7209 & 7.8866 & 7.3895 & 7.8757 & 7.8274 & 7.8497 & 62.2504 & - \\
\hline Place $I_{x}$ & 6 & 2 & 7 & 1 & 8 & 3 & 5 & 4 & - & 0.9727 \\
\hline
\end{tabular}

Table 3: Correlation matrix of factor analysis without glycine and rating of factors in identification by exponential and biotechnical law.

\begin{tabular}{|c|c|c|c|c|c|c|c|c|c|c|}
\hline \multirow{2}{*}{$\begin{array}{c}\text { Influencing } \\
\text { Factors } \\
\text { (characteristic } \\
x \text { ) }\end{array}$} & \multicolumn{8}{|c|}{ Dependent Factors ( $y$ indicators) } & \multirow[b]{2}{*}{ Sum $\sum r$} & \multirow[b]{2}{*}{ Place $I_{x}$} \\
\hline & Leucine & Isoleucine & Histidine & Tyrosine & Lysine & Valine & Methionine & Phenylalanine & & \\
\hline Leucine & 1 & 0.9929 & 0.9757 & 0.9926 & 0.9549 & 0.9940 & 0.9857 & 0.9967 & 7.8925 & 6 \\
\hline Isoleucine & 0.9936 & 1 & 0.9843 & 0.9946 & 0.9834 & 0.9986 & 0.9887 & 0.9972 & 7.9404 & 2 \\
\hline Histidine & 0.9869 & 0.9923 & 1 & 0.9918 & 0.9903 & 0.9903 & 0.9921 & 0.9960 & 7.9397 & 3 \\
\hline Tyrosine & 0.9844 & 0.9889 & 0.9665 & 1 & 0.9533 & 0.9889 & 0.9856 & 0.9938 & 7.8614 & 8 \\
\hline Lysine & 0.9887 & 0.9947 & 0.9925 & 0.9935 & 1 & 0.9945 & 0.9873 & 0.9941 & 7.9453 & 1 \\
\hline Valine & 0.9935 & 0.9981 & 0.9817 & 0.9947 & 0.9849 & 1 & 0.9885 & 0.9961 & 7.9375 & 4 \\
\hline Methionine & 0.9922 & 0.9906 & 0.9797 & 0.9945 & 0.9710 & 0.9923 & 1 & 0.9929 & 7.9132 & 5 \\
\hline Phenylalanine & 0.9920 & 0.9943 & 0.9672 & 0.9925 & 0.9548 & 0.9932 & 0.9750 & 1 & 7.8690 & 7 \\
\hline Sum $\Sigma r$ & 7.9313 & 7.9518 & 7.8476 & 7.9542 & 7.7926 & 7.9519 & 7.9029 & 7.9668 & 63.2991 & - \\
\hline Place $I_{x}$ & 5 & 4 & 7 & 2 & 8 & 3 & 6 & 1 & - & 0.9890 \\
\hline
\end{tabular}

Table 3.1:

\begin{tabular}{|c|c|c|c|c|c|c|c|c|c|c|}
\hline № $\mathbf{p} / \mathbf{p}$ & Product & Leucine & Isoleucine & Histidine & Tyrosine & Glycine & Lysine & Valine & Methionine & $\begin{array}{c}\text { Pheny- } \\
\text { lalanine }\end{array}$ \\
\hline 1 & Beef meat & 1.730 & 1.060 & 0.805 & 0.596 & 1.447 & 2.009 & 1.156 & 0.528 & 0.789 \\
\hline 2 & $\begin{array}{c}\text { Chicken } \\
\text { meat }\end{array}$ & 1.620 & 1.117 & 0.697 & 0.660 & 1.519 & 1.975 & 1.024 & 0.494 & 0.932 \\
\hline
\end{tabular}


The coefficient of correlative variation is 0.9727 , which is significantly less than 0.9985 . In the future, it turned out that in addition to the indicative law, the biotechnical law [4,6,9-15] of the stress excitation of amino acids depending on each other is additionally considered (Table 3 ). With the coefficient of correlative variation 0.9890 in the first place among the influencing variables was lysine, and among the indicators -phenylalanine. Thus, the correlative variation is very sensitive to the composition of amino acids and products. This fact in the future will reveal the rational compositions, structures and functions of amino acids in different systems under study.

\section{The Law of the Relationship Between Amino Acids}

It is expressed by an equation of the form

$$
y=a_{1} x^{a^{2}} \pm a_{3} x^{a^{4}} \exp \left(-a_{5} x^{a^{6}}\right.
$$

where $\mathrm{y}$ - amino acid content in the product as an indicator ( $\mathrm{g}$ per $100 \mathrm{~g}$ of product),

$\mathrm{x}$ - amino acid content of the product as an influencing variable (g per $100 \mathrm{~g}$ of product),

$a_{1 . .} a_{6}$ - the parameters of the model (2) taking the numerical values in the course of structural-parametric identification in the software environment CurveExpert-1.40. Formula (2) shows three types of stress-induced amino acids under the influence of each other: positive, neutral and negative. Neutral type appears only without shiitake mushrooms, that is, when the amino acid content changes from 0 to 2 (maximum 2.009 for beef). The maximum concentrations of nine amino acids without shiitaki mushrooms are in two products-beef and chicken meat. In the amino acid content range from 2 to 7 in Table 1 there are no types of products (except mushrooms). Therefore, it is necessary to add new products to the list and Table 1.

In the concentration range from 0 to 7 , two types of behavior appear:

A. positive behavior, with a positive sign in front of the second component of the formula (2), when with increasing content of the influencing amino acid, the content of the dependent amino acid increases according to the biotechnical law of stress excitation;

B. negative behavior, with a negative sign, when the content of the dependent amino acid is inhibited from the action of the wagging amino acid. These two types provide optima for the interaction of essential amino acids.

\section{Correlation Matrix}

Table 4: Correlation matrix of super strong binary relations by exponential law at the level of adequacy $r \geq 0,99$.

\begin{tabular}{|c|c|c|c|c|}
\hline \multirow{2}{*}{$\begin{array}{c}\text { Influencing Factors } \\
\text { (characteristic } x \text { ) }\end{array}$} & Leucine & Isoleucine & Tyrosine & Dependent Factors $(y$ indicators) \\
\cline { 2 - 5 } & & 0.9910 & 0.9907 & 0.9937 \\
\hline Leucine & & & 0.9918 & 0.9972 \\
\hline Isoleucine & & & & 0.9909 \\
\hline Tyrosine & 0.9918 & 0.9969 & 0.9922 & 0.9924 \\
\hline Valine & 0.9910 & & 0.9921 & \\
\hline
\end{tabular}

Table 5: Correlation matrix superpowered binary relations exponential and biotech law, when the correlation level $r \geq 0,99$.

\begin{tabular}{|c|c|c|c|c|c|c|c|c|}
\hline \multirow{2}{*}{$\begin{array}{c}\text { Influencing } \\
\text { Factors } \\
\text { (characteristic } \\
x \text { ) }\end{array}$} & \multicolumn{8}{|c|}{ Dependent Factors ( $y$ indicators) } \\
\hline & Leucine & Isoleucine & Histidine & Tyrosine & Lysine & Valine & Methionine & Phenylalanine \\
\hline Leucine & & 0.9929 & & 0.9926 & & 0.9940 & & 0.9967 \\
\hline Isoleucine & 0.9936 & & & 0.9946 & & 0.9986 & & 0.9972 \\
\hline Histidine & & 0.9923 & & 0.9918 & 0.9903 & 0.9903 & 0.9921 & 0.9960 \\
\hline Tyrosine & & & & & & & & 0.9938 \\
\hline Lysine & & 0.9947 & 0.9925 & 0.9935 & & 0.9945 & & 0.9941 \\
\hline Valine & 0.9935 & 0.9981 & & 0.9947 & & & & 0.9961 \\
\hline Methionine & 0.9922 & 0.9906 & & 0.9945 & & 0.9923 & & 0.9929 \\
\hline Phenylalanine & 0.9920 & 0.9943 & & 0.9925 & & 0.9932 & & \\
\hline
\end{tabular}


From Table 2, choose a binary relationship with a correlation coefficient of at least 0.99 (Table 4). The neutral behavior of amino acids receives only 15 binary bonds at the level of superstrong adequacy (or $10015 / 72=20.83 \%$ ). We will do the same with the data in Table 3. Table 5 shows a significant increase in the number of super strong links, $33 \%$ or $45.83 \%$. The matrix remained completeeight rows and columns. However, the behavior of biological objects is characterized, in addition to the trend (2) vibrational adaptation $[6,12,14,15]$. To identify the wavelet signals from the amino acid behavior under mutual influence, it is necessary to significantly expand Table 1 also with interchangeable amino acids. Especially it is necessary to pay attention to the types of products that give a concentration of 2 to 7 .

\section{Binary Relation Graphs}

The effect of each essential amino acid on the concentration of other amino acids is shown in four graphs, which are arranged in figures in descending correlation coefficient. Of the 72 graphs in the article shows a total of 32 graphics (Figures 1-8). They provide a visual representation of the variations of formula (2). The second component of the general model (2) shows a different level of adaptability (positive or negative) dependent on the influencing amino acid by the coefficient of adaptability.

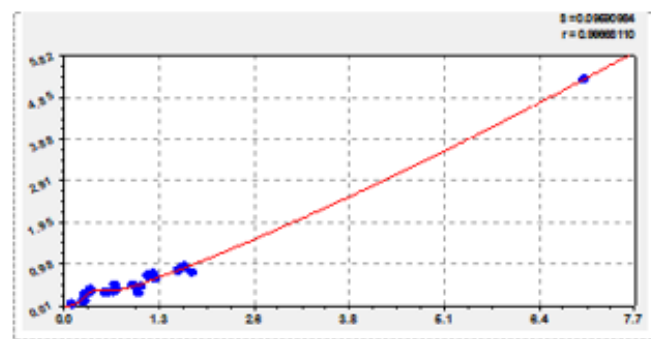

1) effect on phenylalanine 0.9967

ind

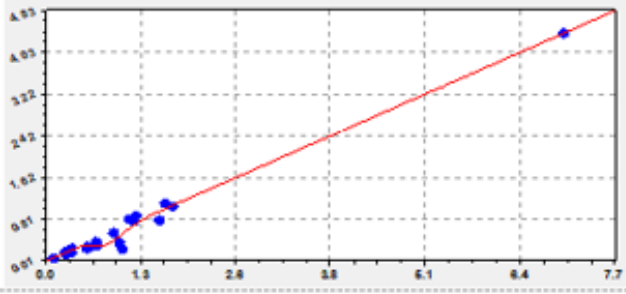

3) the effect of a change in isoleucine 0.9929

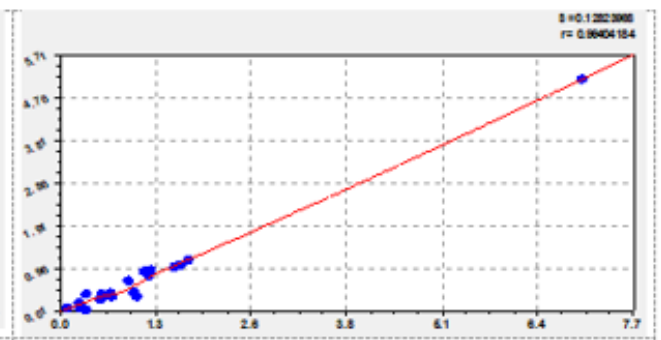

2) the impact on the change of valine 0.9940
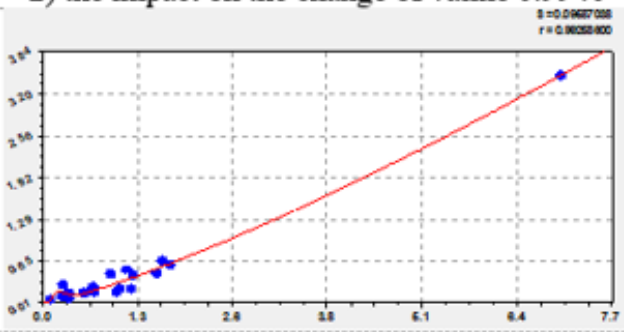

4) the effect of a change in tyrosine 0.9926

Figure 1: Graphs of the effect of leucine on other essential amino acids (in the upper right corner: $S$ - variance; $r$ - correlation coefficient).

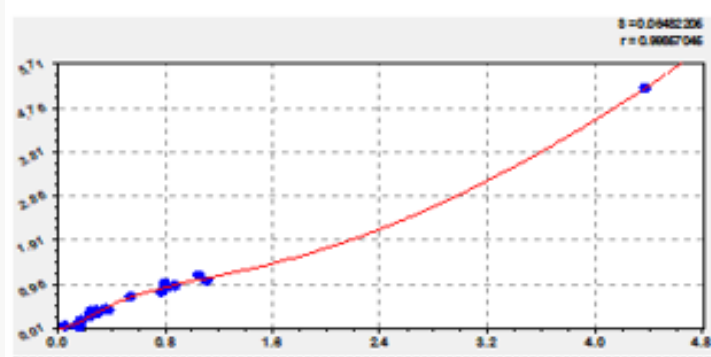

1) the impact on the change of valine 0.9986

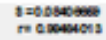

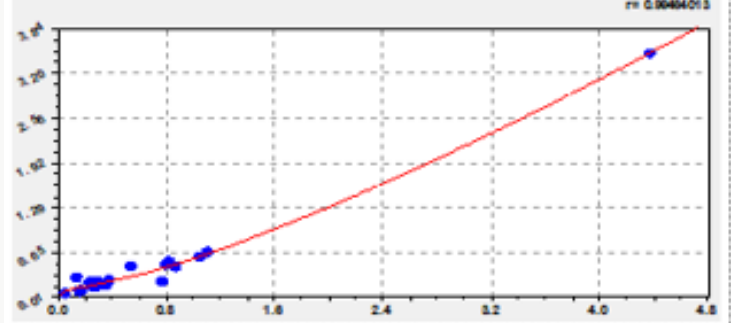

3) the effect of a change in tyrosine 0.9946

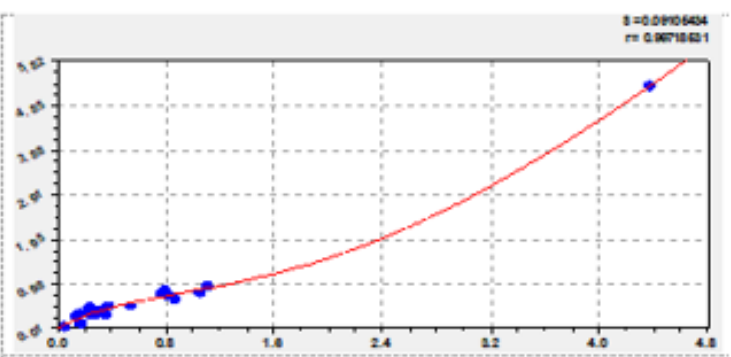

2) effect on phenylalanine 0.9972

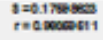

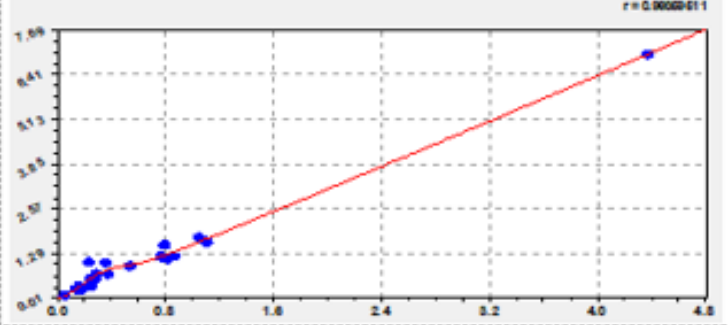

4) the impact on the change of leucine 0.9936

Figure 2: Graphs of the effect of isoleucine on other essential amino acids. 


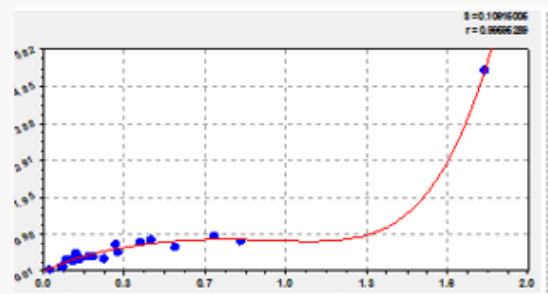

1) effect on phenylalanine 0.9960

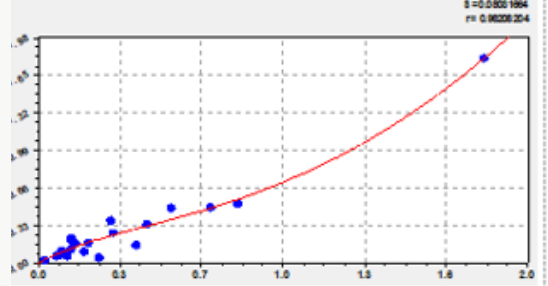

3) the effect of a change in methionine 0.9921

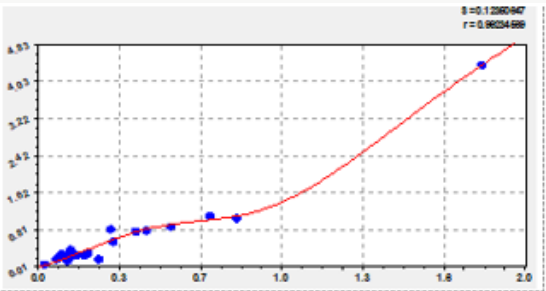

2) the effect of a change in isoleucine 0.9923

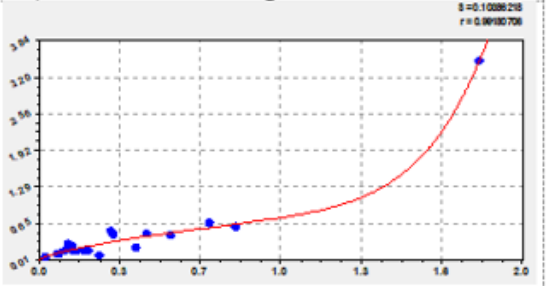

4) the effect of a change in tyrosine 0.9918

Figure 3: Graphs of the effect of histidine on other essential amino acids.

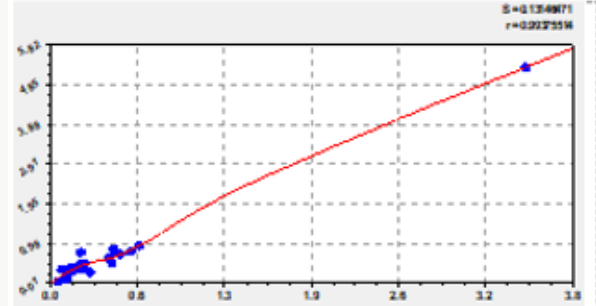

1) effect on phenylalanine 0.9938

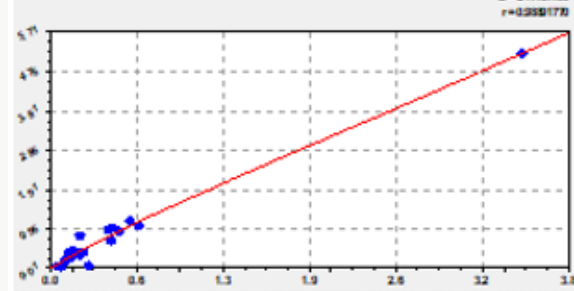

3) the impact on the change of valine 0.9889

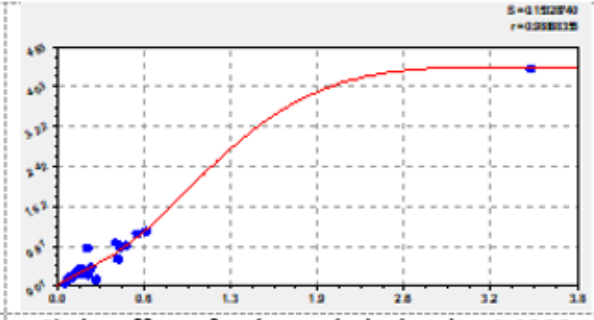

2) the effect of a change in isoleucine 0.9889

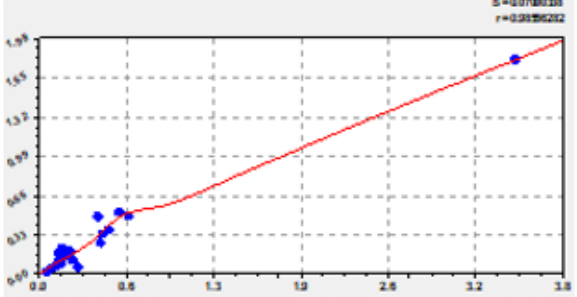

4) the effect of a change in methionine 0.9856

Figure 4: Graphs of the effect of tyrosine on other essential amino acids.

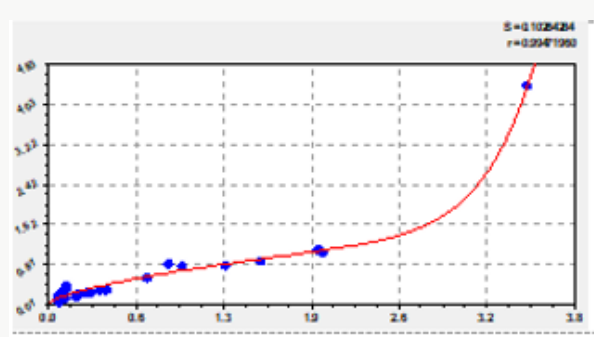

1) the effect of a change in isoleucine 0.9947

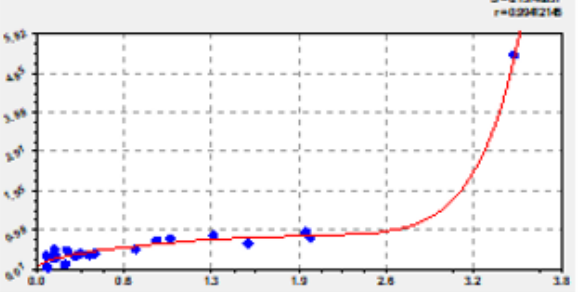

3) effect on phenylalanine 0.9941

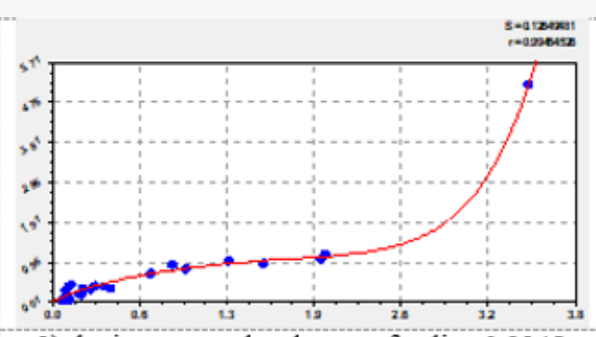

2) the impact on the change of valine 0.9945

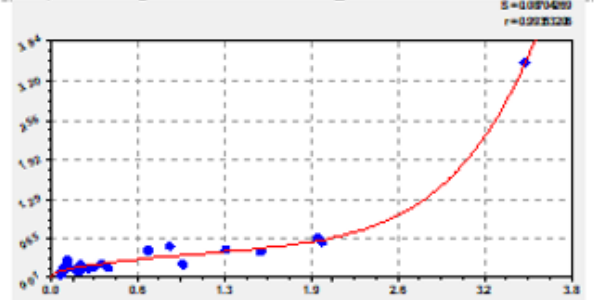

4) the effect of a change in tyrosine 0.9935

Figure 5: Charts the influence of the lysine to other essential amino acids. 


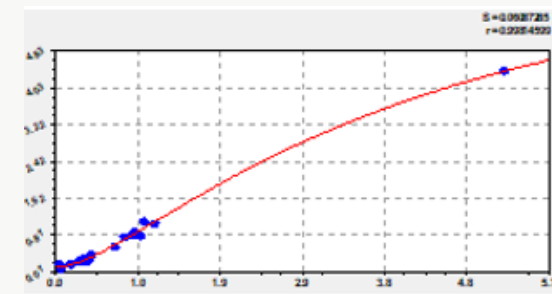

The effect of a change in isoleucine 0.9981

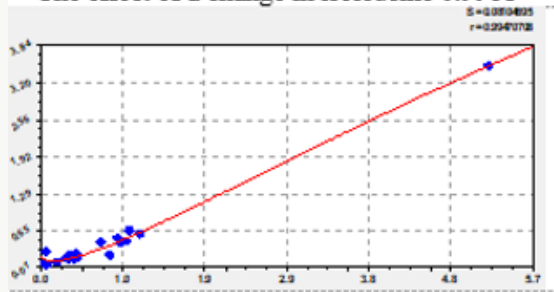

The effect of a change in tyrosine 0.9947

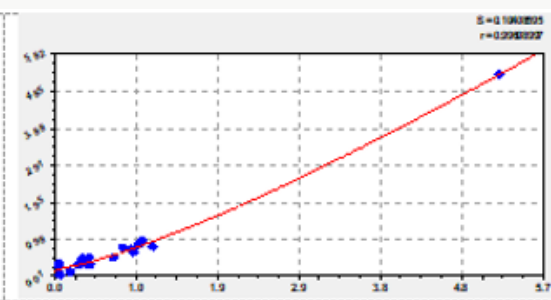

Effect on phenylalanine 0.9961

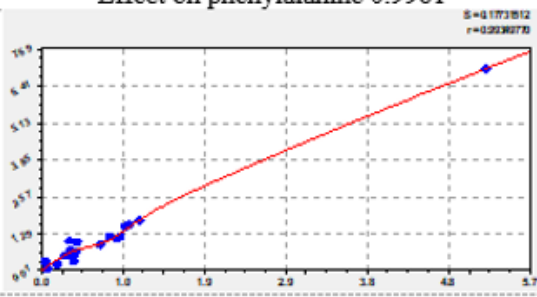

The impact on the change of leucine 0.9935

Figure 6: Graphs of valine effect on other essential amino acids.

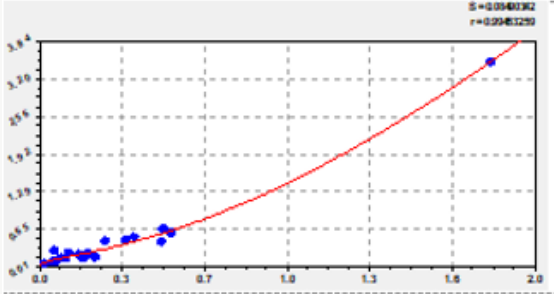

1) the effect of a change in tyrosine 0.9945

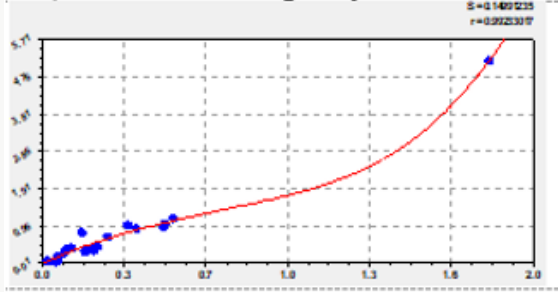

3) the impact on the change of valine 0.9923

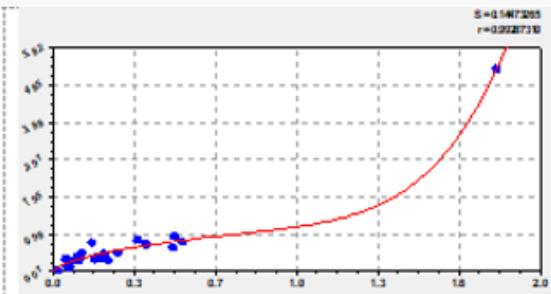

2) effect on phenylalanine 0.9929

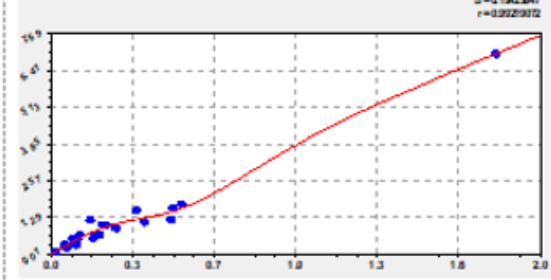

4) the impact on the change of leucine 0.9922

Figure 7: Graphs of the effect of methionine on other essential amino acids.

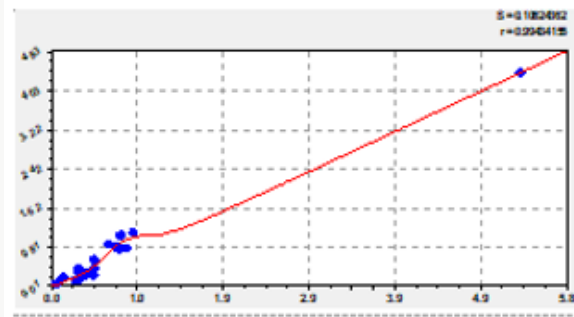

1) the effect of a change in isoleucine 0.9943

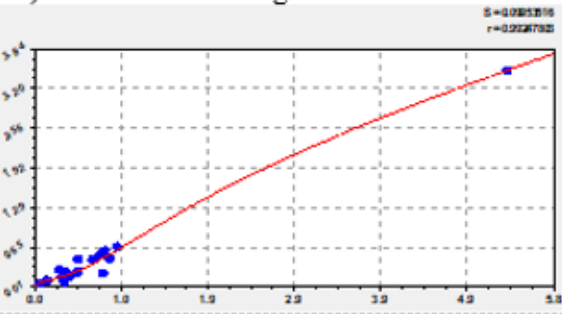

3) the effect of a change in tyrosine 0.9925

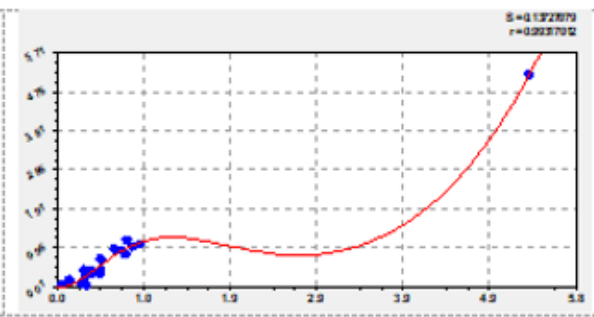

2) the impact on the change of valine 0.9932

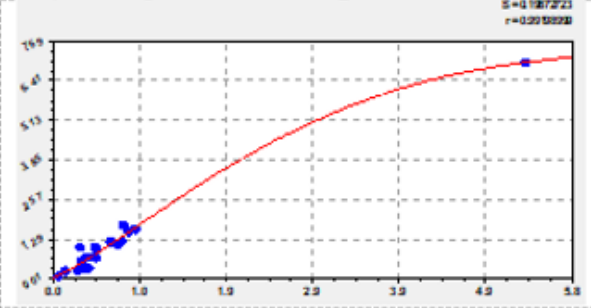

4) the impact on the change of leucine 0.9920

Figure 8: Charts the influence of phenylalanine to other essential amino acids. 
On the charts, the positive behavior of essential amino acids is shown as a convex curve, and the negative behavior is shown as a concave curve. On the effect of histidine and methionine it is possible to estimate the minimum interval of the concentration of essential amino acids with neutral type. As can be seen from the graphs in Figure 3, the neutral behavior type is from 0 to 0.5 . The convexity or concavity of the graph has a different length along the abscissa axis. It is obvious that the addition of the list from Table 1 with additional products having amino acid concentration in the range from 2 to 7 , will allow to specify the parameters of the model (2) and add a wave function. However, in our opinion, the nature (design) (2) of the expansion of the list of products will not change. Graphs of the effect of lysine on other amino acids have a concave appearance, which relates them to the negative effect. At the same time, there is a steep rise of curves, more than five times after the concentration of lysine 2.5-2.8. Figure 7 shows the multidirectional effect of methionine on other amino acids along the different length of the concave or convex part. For example, the positive effect of phenylalanine on the change of isoleucine is observed in a short period of abscissa from 0.3 to 1.3. But the effect of phenylalanine on the change of leucine is observed throughout the axis of abscissa.

\section{Parameters of a Two-Member Model}

Table 6: Parameters of the laws of mutual influence of essential amino acids.

\begin{tabular}{|c|c|c|c|c|c|c|c|}
\hline \multirow{2}{*}{$\begin{array}{l}\text { Influencing } \\
\text { variable }\end{array}$} & \multirow{2}{*}{$\begin{array}{l}\text { The dependent } \\
\text { measure }\end{array}$} & \multicolumn{6}{|c|}{ Regularity $y=a_{1} x^{a_{2}}+a_{3} x^{a_{4}} \exp \left(-a_{5} x^{a_{6}}\right)$} \\
\hline & & $a_{1}$ & $a_{2}$ & $a_{3}$ & $a_{4}$ & $a_{5}$ & $a_{6}$ \\
\hline \multirow{7}{*}{ Leucine } & Isoleucine & 0.62905 & 0.99985 & $-6.22460 \mathrm{e} 8$ & 18.71644 & 22.22097 & 1 \\
\hline & Histidine & 0.46897 & 0.69905 & -203.9818 & 5.54825 & 6.84333 & 1 \\
\hline & Tyrosine & 0.31097 & 1.24392 & 1581527.7 & 6.39206 & 30.05027 & 1 \\
\hline & Lysine & 1.76396 & 0.36696 & -10.59470 & 1.39906 & 2.30544 & 1 \\
\hline & Valine & 0.64740 & 1.07056 & $-2.25214 \mathrm{e} 9$ & 20.99985 & 24.13061 & 1 \\
\hline & Methionine & 0.48396 & 0.67505 & -0.29303 & 0.55052 & 0.23317 & 1.99910 \\
\hline & Phenylalanine & 0.49792 & 1.21483 & 9595683.7 & 9.34738 & 22.79351 & 1 \\
\hline \multirow{7}{*}{ Isoleucine } & Leucine & 1.52478 & 1.02860 & 9999.058 & 5.12916 & 14.70289 & 1 \\
\hline & Histidine & 0.72596 & 0.61893 & -14.41016 & 2.32975 & 4.77636 & 1 \\
\hline & Tyrosine & 0.53135 & 1.27240 & 0.28389 & 0.53468 & 2.90970 & 0.96123 \\
\hline & Lysine & 0.38710 & 0.49498 & 1180.425 & 5.57652 & 6.79209 & 0.50461 \\
\hline & Valine & 0.45360 & 1.64113 & 110.61568 & 2.64866 & 5.26502 & 0.54772 \\
\hline & Methionine & 0.47411 & 0.90274 & $-5.01711 \mathrm{e} 9$ & 17.79059 & 26.41250 & 1 \\
\hline & Phenylalanine & 1.82668 & 1.01048 & -1.62256 & 1.77226 & 0.47849 & 0.98417 \\
\hline \multirow{7}{*}{ Histidine } & Leucine & 27.41879 & 0.87946 & -25.49275 & 0.90894 & 0.0024500 & 6.46573 \\
\hline & Isoleucine & 2.37692 & 1.13214 & -1461.648 & 7.62827 & 7.35461 & 1 \\
\hline & Tyrosine & 13.24185 & 0.71994 & -12.51376 & 0.72283 & 0.0021289 & 7.06274 \\
\hline & Lysine & 1.84717 & 1.08523 & 18030.334 & 6.91718 & 11.01985 & 1 \\
\hline & Valine & 2.68511 & 1.12890 & -196399.8 & 10.54932 & 12.37680 & 1 \\
\hline & Methionine & 3.80692 & 1.14221 & -3.87156 & 1.34613 & 0.22711 & 1.01776 \\
\hline & Phenylalanine & 9.10329 & 1.11668 & -8.35584 & 1.28670 & 0.0058888 & 7.06020 \\
\hline \multirow{7}{*}{ Tyrosine } & Leucine & 2.59556 & 0.79268 & -3.75738 & 2.23306 & 2.86196 & 1 \\
\hline & Isoleucine & 1.12082 & 0.78105 & 501.15485 & 5.56113 & 6.29215 & 0.56901 \\
\hline & Histidine & 0.27432 & 0.36988 & 10.20796 & 3.95035 & 1.99234 & 0.99868 \\
\hline & Lysine & 1.19035 & 0.86085 & 33729.083 & 8.35215 & 0.24870 & 1 \\
\hline & Valine & 1.51279 & 0.98152 & 0.43938 & 1.04759 & 1.13609 & 1 \\
\hline & Methionine & 0.59313 & 0.88555 & $6.42624 \mathrm{e} 8$ & 15.23516 & 24.55075 & 1 \\
\hline & Phenylalanine & 1.76155 & 0.87936 & -954.86339 & 5.43980 & 8.87500 & 1 \\
\hline
\end{tabular}




\begin{tabular}{|c|c|c|c|c|c|c|c|}
\hline \multirow{7}{*}{ Lysine } & Leucine & 0.00075787 & 7.01566 & 1.14549 & 0.45402 & 0 & 0 \\
\hline & Isoleucine & $1.36349 \mathrm{e}-5$ & 9.78172 & -0.70109 & 0.62975 & 0.00085077 & 1 \\
\hline & Histidine & 10.01954 & 0.35029 & -9.79594 & 0.35070 & 0.012317 & 1.67629 \\
\hline & Tyrosine & 0.0015120 & 6.01054 & 0.38061 & 0.46654 & 0 & 0 \\
\hline & Valine & 43.74284 & 1.05348 & -42.92471 & 1.06386 & $2.82820 \mathrm{e}-6$ & 7.29991 \\
\hline & Methionine & 0.0023803 & 4.95210 & 0.30405 & 0.56965 & 0 & 0 \\
\hline & Phenylalanine & $6.48222 \mathrm{e}-6$ & 10.79484 & 0.67506 & 0.45753 & 0.0070620 & 3.91832 \\
\hline \multirow{7}{*}{ Valine } & Leucine & 1.68957 & 0.86202 & -117442.4 & 10.37155 & 13.19709 & 1 \\
\hline & Isoleucine & 8.89512 & 0.31783 & -3.15020 & 0.37852 & 0.47580 & 1 \\
\hline & Histidine & 0.39220 & 0.92312 & $1.52857 \mathrm{e} 9$ & 30.20624 & 22.94088 & 1 \\
\hline & Tyrosine & 5.55544 & 0.19325 & -5.74250 & 0.21851 & 0.13204 & 1 \\
\hline & Lysine & 0.25082 & 0.32497 & 2549189.8 & 8.13192 & 14.52145 & 0.37751 \\
\hline & Methionine & 0.28301 & 0.65777 & 0.80760 & 5.65024 & 1.75757 & 1 \\
\hline & Phenylalanine & 24.03443 & 0.29124 & -23.90412 & 0.29549 & 0.028464 & 1 \\
\hline \multirow{7}{*}{ Methionine } & Leucine & 4.09975 & 0.91089 & -10326.19 & 6.26159 & 10.67398 & 1 \\
\hline & Isoleucine & 2.73865 & 0.86374 & -11.08877 & 1.73777 & 3.36038 & 0.78234 \\
\hline & Histidine & 0.50538 & 0.54222 & 40603.795 & 10.31218 & 9.20729 & 1 \\
\hline & Tyrosine & 8.66195 & 0.51160 & -8.30592 & 0.51879 & 0.14181 & 1.36907 \\
\hline & Lysine & 1.28140 & 0.76009 & 32657.836 & 6.21189 & 9.37323 & 0.63848 \\
\hline & Valine & 6.11986 & 1.09075 & -4.51311 & 1.31031 & 0.036284 & 4.15755 \\
\hline & Phenylalanine & 11.68668 & 0.79065 & -10.57130 & 0.82831 & 0.0067570 & 6.19146 \\
\hline \multirow{7}{*}{ Phenylalanine } & Leucine & 0.49906 & 0.54080 & 1.69424 & 1.51814 & 0.24648 & 1 \\
\hline & Isoleucine & 0.78238 & 1.03541 & 1492111.7 & 13.06361 & 15.57889 & 1 \\
\hline & Histidine & 0.15533 & 0.44260 & 3.56380 & 3.23930 & 1.77093 & 0.75946 \\
\hline & Tyrosine & 0.97692 & 0.76653 & -4.16141 & 1.55679 & 2.59353 & 0.73740 \\
\hline & Lysine & 0.56678 & 1.09143 & 630.15239 & 6.90628 & 6.09093 & 1 \\
\hline & Valine & 0.0046610 & 4.20571 & 7.63182 & 2.40205 & 1.91020 & 1 \\
\hline & Methionine & 0.35060 & 0.98095 & 1886.0969 & 8.08271 & 9.83812 & 1 \\
\hline
\end{tabular}

Table 7: Behavior of essential amino acids.

\begin{tabular}{|c|c|c|c|c|c|c|c|c|c|c|}
\hline \multirow{2}{*}{$\begin{array}{l}\text { Influencing Factors } \\
\text { (characteristic } x \text { ) }\end{array}$} & \multicolumn{8}{|c|}{ Dependent Factors ( $y$ indicators) } & \multirow{2}{*}{$\begin{array}{l}\text { Sum of } \\
\text { codes }\end{array}$} & \multirow{2}{*}{ Place } \\
\hline & Leucine & Isoleucine & Histidine & Tyrosine & Lysine & Valine & Methionine & Phenylalanine & & \\
\hline Leucine & 0 & -1 & -1 & 1 & -1 & -1 & -1 & 1 & -3 & 5 \\
\hline Isoleucine & 1 & 0 & -1 & 1 & 1 & 1 & -1 & -1 & 1 & 3 \\
\hline Histidine & -1 & -1 & 0 & -1 & 1 & -1 & -1 & -1 & -5 & 6 \\
\hline Tyrosine & -1 & 1 & 1 & 0 & 1 & 1 & 1 & -1 & 3 & 2 \\
\hline Lysine & 1 & -1 & -1 & 1 & 0 & -1 & 1 & 1 & 1 & 3 \\
\hline Valine & -1 & -1 & 1 & -1 & 1 & 0 & 1 & -1 & -1 & 4 \\
\hline Methionine & -1 & -1 & 1 & -1 & 1 & -1 & 0 & -1 & -3 & 5 \\
\hline Phenylalanine & 1 & 1 & 1 & -1 & 1 & 1 & 1 & 0 & 5 & 1 \\
\hline Sum of codes & -1 & -3 & 1 & -1 & 5 & -1 & 1 & -3 & -2 & - \\
\hline Place & 3 & 4 & 2 & 3 & 1 & 3 & 2 & 4 & - & - \\
\hline
\end{tabular}


Model parameters (2) are given in Table 6 The positive form of the equation (2) is used in the recording. Then the negative type is easily determined by the negative sign before the model parameter $a_{3}$. Then you can classify (Table 7) three types of behavior of essential amino acids (code: 1 - positive; 0 - neutral; -1 - negative). Apparently, for the most complete amino acid system, the total sum of codes will approach zero. As a variable on the positive effect in the first place - phenylalanine, and among the dependent indicators - lysine.

Table 8: Rating of products by content of essential amino acids.

\begin{tabular}{|c|c|c|c|c|c|c|c|c|c|c|c|}
\hline S.No. & Product & Leu-cine & $\begin{array}{l}\text { Isoleu- } \\
\text { cine }\end{array}$ & $\begin{array}{c}\text { Histi- } \\
\text { dine }\end{array}$ & Tyro-sine & Ly-sine & Va-line & $\begin{array}{l}\text { Methi- } \\
\text { onine }\end{array}$ & $\begin{array}{l}\text { Pheny- } \\
\text { lalanine }\end{array}$ & $\sum R$ & $\begin{array}{c}\text { Product } \\
\text { place }\end{array}$ \\
\hline 1 & $\begin{array}{l}\text { Milk for } \\
\text { women }\end{array}$ & 21 & 21 & 21 & 21 & 20 & 19 & 21 & 21 & 165 & 21 \\
\hline 2 & Cow's milk & 18 & 17 & 19 & 18 & 13 & 17 & 17 & 20 & 139 & 19 \\
\hline 3 & Kefir & 20 & 18 & 20 & 19 & 14 & 18 & 18 & 19 & 146 & 20 \\
\hline 4 & Curd & 9 & 7 & 6 & 5 & 7 & 7 & 6 & 7 & 54 & 8 \\
\hline 5 & Chicken egg & 6 & 4 & 7 & 3 & 6 & 5 & 4 & 5 & 40 & 6 \\
\hline 6 & Beef meat & 1 & 2 & 1 & 2 & 1 & 1 & 1 & 3 & 12 & 2 \\
\hline 7 & Chicken meat & 2 & 1 & 2 & 1 & 2 & 2 & 2 & 1 & 13 & 3 \\
\hline 8 & Beef liver & 3 & 5 & 4 & 4 & 4 & 3 & 5 & 2 & 30 & 4 \\
\hline 9 & Cod & 4 & 3 & 3 & 6 & 3 & 4 & 3 & 6 & 32 & 5 \\
\hline 10 & Rice grits & 8 & 9 & 14 & 12 & 15 & 8 & 7 & 17 & 90 & 13 \\
\hline 11 & Semolina & 16 & 13 & 10 & 15 & 10 & 11 & 15 & 10 & 100 & 14 \\
\hline 12 & Buckwheat & 10 & 11 & 9 & 14 & 8 & 13 & 10 & 11 & 86 & 10 \\
\hline 13 & Oatmeal & 12 & 10 & 12 & 9 & 9 & 12 & 9 & 12 & 85 & 9 \\
\hline 14 & Millet grits & 7 & 16 & 12 & 11 & 12 & 14 & 8 & 9 & 89 & 12 \\
\hline 15 & Pearl barley & 13 & 13 & 11 & 17 & 11 & 15 & 11 & 14 & 105 & 15 \\
\hline 16 & Pea & 5 & 6 & 5 & 10 & 5 & 6 & 12 & 4 & 53 & 7 \\
\hline 17 & Wheat flour & 14 & 12 & 18 & 16 & 18 & 10 & 14 & 16 & 118 & 16 \\
\hline 18 & Pasta & 11 & 8 & 15 & 8 & 16 & 9 & 13 & 8 & 88 & 11 \\
\hline 19 & Rye bread & 19 & 20 & 16 & 7 & 17 & 20 & 19 & 18 & 136 & 18 \\
\hline 20 & Wheat bread & 15 & 15 & 17 & 13 & 19 & 16 & 16 & 15 & 126 & 17 \\
\hline 21 & Liver & 17 & 19 & 8 & 20 & 21 & 21 & 20 & 13 & 139 & 19 \\
\hline 22 & $\begin{array}{c}\text { Shiitake } \\
\text { mushrooms }\end{array}$ & 0 & 0 & 0 & 0 & 0 & 0 & 0 & 0 & 0 & 1 \\
\hline
\end{tabular}

Let's check the initial data of Table 1 for the quality factor.

Any of the factors is the vector orientation and the two possible behaviors:

a) better more on the vector better worse, the rank is given to the maximum, and the ranking is performed in descending order of the factor values;

b) it is better to lower, so the rank is given to a minimum, and the ranking is performed by increasing the values of the factor.

\section{The Quality of the Source Data and Ratings of Products}

A tabular model is a good-quality and relatively complete table of input data for statistical modeling by identification of stable laws and regularities. The quality factor is understood as the accuracy of the numbers, the primacy of the indicators (the factor analysis is not initially permitted secondary received, calculations, parameters), consistency of the description of the object of the studies consider many parameters. As a result, we get the distribution of places in descending order (Table 8). 
theoretically possible in the first place. For the second place the sum of ranks is 12 . Next, we can take places for the explanatory variable, and the sum of ranks from Table 8 for the indicator.
After identification of the general trend formula [13], we obtained (Figure 9) formula
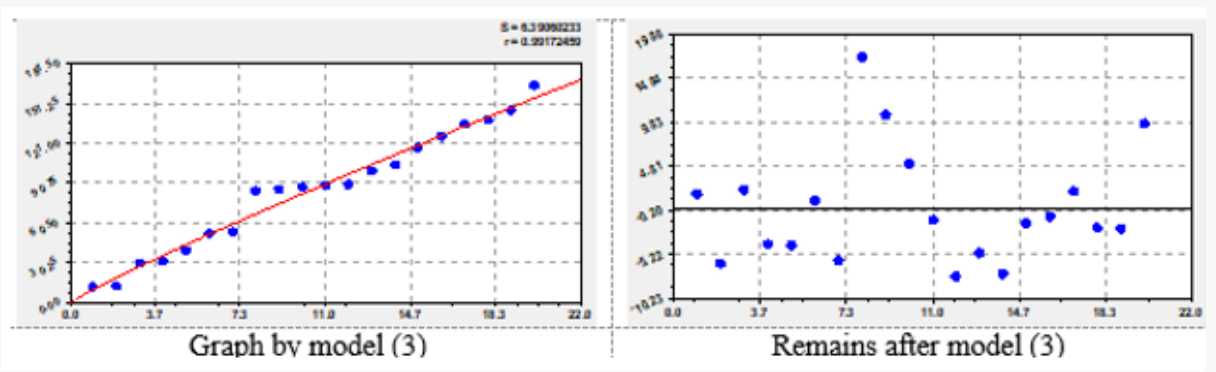

Figure 9: Product rating charts from table 1 data.

$$
\sum R=10.25609(I-1)^{0.90719}
$$

The remnants after (3) show that wave function is possible in addition to the trend. Half amplitude reaches a share of $100 \times$
$17.3524 / 85=20.41 \%$. In the article we do not consider vibrational adaptation, as we need a table for all 20 amino acids. Each of the eight amino acids will be considered separately.

\section{Ranking Distribution of Amino Acids}
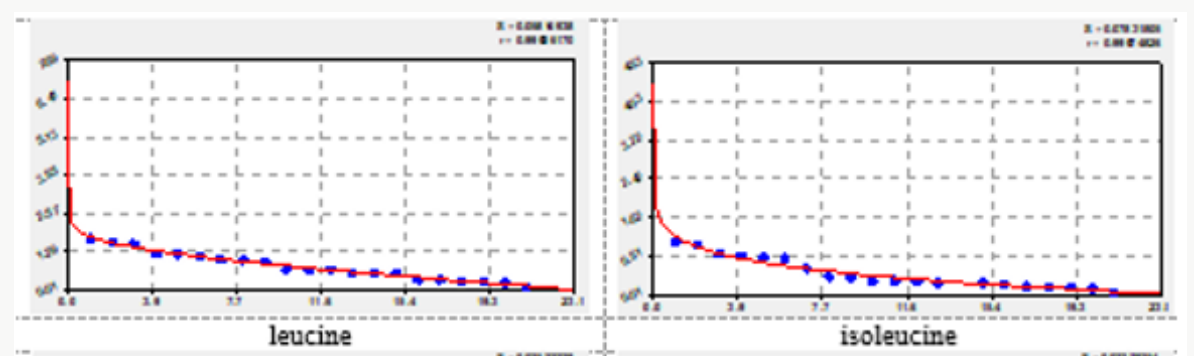

제
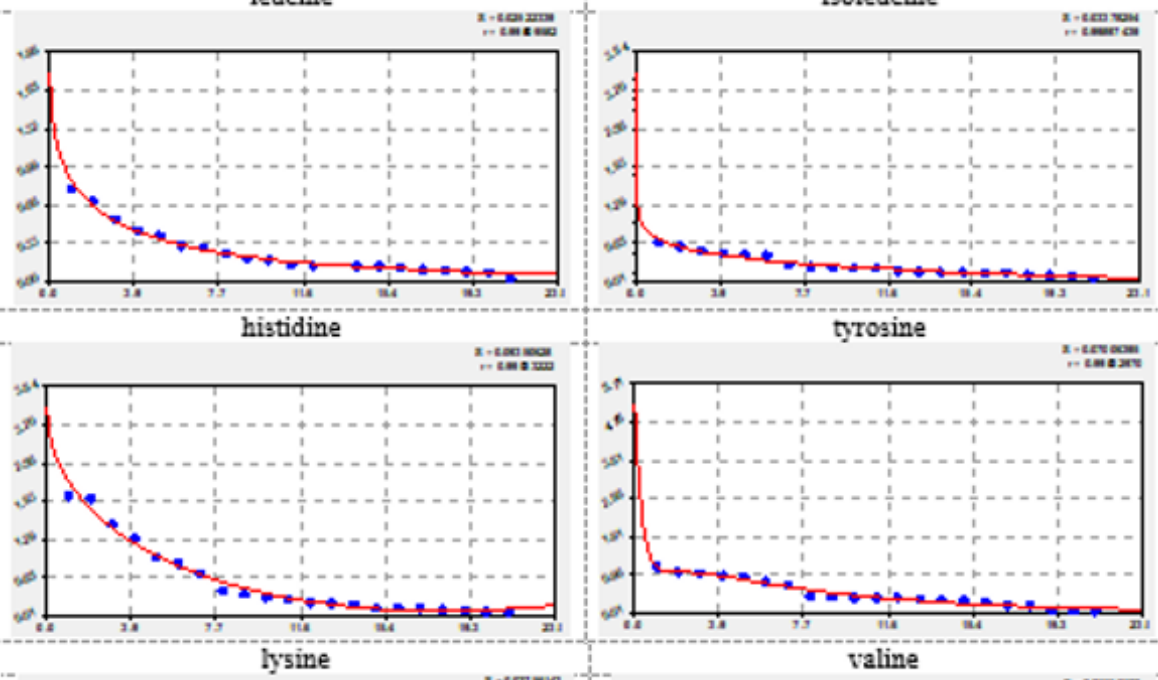

n-ternas
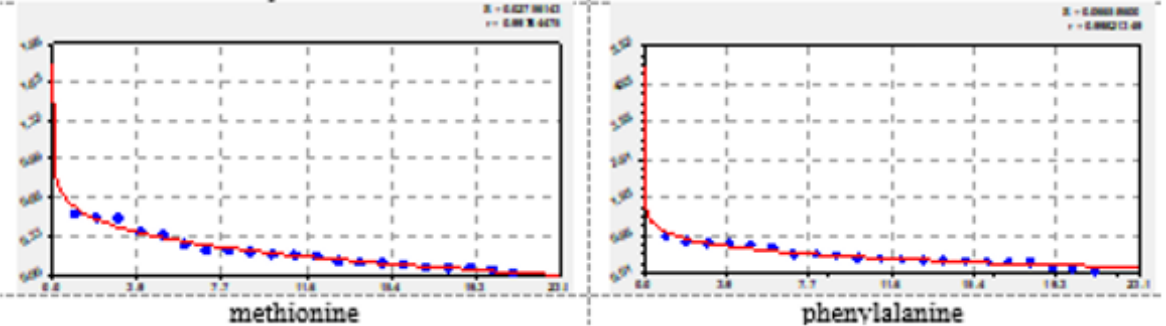

Figure 10: Product rating charts from table 1 data. 
For statistical modeling, the ranks $R$ must start from zero, with the rank distributions subject to the exponential law (growth or death). After the identification of the generalized trend [13] are obtained (Figure 10) formulas:

a) rank distribution of leucine

$$
L=6.99985 \exp \left(-0.0069383 R_{L}\right)-5.16790 R_{I}^{0.044232}
$$

b) rank distribution of isoleucine

$$
I=4.39916 \exp \left(-0.00062254 R_{I}\right)-3.16653 R_{I}^{0.097771}
$$

c) rank distribution of histidine

$$
H=1.79477 \exp \left(-0.72614 R_{H}^{0.48719}\right)
$$

d) rank distribution of tyrosine

$$
Y=3.49967-2.78248 R_{Y}^{0.068084}
$$

e) ranking distribution of lysine

$$
K=3.47649 \exp \left(0.021832 R_{K}\right)-1.31631 R_{K}^{0.50137} \exp \left(-0.0056940 R_{K}\right)
$$

f) rank distribution of valine

$$
V=5.20003 \exp \left(-2.89763 R_{V}\right)+2.56943 R_{V}^{0.99053} \exp \left(-1.08777 R_{V}^{0.56874}\right)
$$

g) rank distribution of methionine

$$
M=1.79957 \exp \left(-0.00098714 R_{M}\right)-1.21781 R_{M}^{0.11680}
$$

h) rank distribution of phenylalanine

$$
F=5.29876-4.23519 R_{F}^{0.061528}
$$

\begin{tabular}{|c|c|c|c|c|c|c|c|c|c|c|}
\hline \multirow{2}{*}{$\begin{array}{c}\text { Influencing } \\
\text { Factors } \\
\text { (characteristic } \\
x \text { ) }\end{array}$} & \multicolumn{8}{|c|}{ Dependent Factors ( $y$ indicators) } & \multirow[b]{2}{*}{ Sum $\Sigma S$} & \multirow[b]{2}{*}{ Place $I_{x}^{S}$} \\
\hline & Leucine & Isoleucine & Histidine & Tyrosine & Lysine & Valine & Methionine & Pheny-lalanine & & \\
\hline Leucine & 0,0581 & 0,1193 & 0,0947 & 0,0959 & 0,2976 & 0,1282 & 0,0718 & 0,0959 & 0,9615 & 4 \\
\hline Isoleucine & 0,1760 & 0,0783 & 0,0764 & 0,0841 & 0,1583 & 0,0648 & 0,0621 & 0,0911 & 0,7911 & 1 \\
\hline Histidine & 0,2593 & 0,1325 & 0,0252 & 0,1039 & 0,1344 & 0,1631 & 0,0803 & 0,1092 & 1,0079 & 5 \\
\hline Tyrosine & 0,2666 & 0,1533 & 0,1144 & 0,0338 & 0,2926 & 0,1747 & 0,0700 & 0,1315 & 1,2369 & 8 \\
\hline Lysine & 0,2463 & 0,1026 & 0,0545 & 0,0870 & 0,0935 & 0,1265 & 0,0639 & 0,1315 & 0,9058 & 3 \\
\hline Valine & 0,1773 & 0,0609 & 0,0823 & 0,0810 & 0,1728 & 0,0701 & 0,0624 & 0,1041 & 0,8109 & 2 \\
\hline Methionine & 0,1943 & 0,1407 & 0,0867 & 0,0849 & 0,2389 & 0,1499 & 0,0276 & 0,1447 & 1,0677 & 6 \\
\hline Phenylalanine & 0,1967 & 0,1062 & 0,1132 & 0,0995 & 0,2879 & 0,1373 & 0,0919 & 0,0666 & 1,0993 & 7 \\
\hline Sum & 1,5746 & 0,8938 & 0,6474 & 0,6701 & 1,6760 & 1,0146 & 0,5300 & 0,8746 & 7,8811 & - \\
\hline Place & 7 & 5 & 2 & 3 & 8 & 6 & 1 & 4 & - & 0.1231 \\
\hline
\end{tabular}

The sum of the squares of deviations from the equations of binary and unary (by ranks) relations between eight essential amino acids is written in the dispersion matrix (Table 9). As the influencing variable on the first place on minimum of the sum of dispersions there was isoleucine, and among dependent indicators - methionine. The average variance for all $8^{2}=64$ cells of the matrix is $\bar{D}=0.1231$.

Table 9: The variance matrix of the residuals after the full factor analysis and ranking of factors when identifying significant and biotech law.

\section{Conclusion}

We have extended the principle of correlative variation not only to Charles Darwin organisms, but also to populations (in the article population of eight amino acids) and even to any biological, biotechnical and technical systems [13]. This principle allows to compare heterogeneous systems on one or some set of factors by functional connectivity. The coefficient of correlative variation, as a generalized criterion for comparing different sets of homogeneous 
biological objects, gets a very high value. For example, populations of genes $[14,15]$ obtained the correlative coefficient of variation not less than 0.9999. In the example of this article, the level of adequacy for the set of eight essential amino acids is not less than 0.99. This makes it possible in the future to create the most complete table of contents and other indicators for a system of 20 amino acids and hundreds of objects, including products. Functional connectivity between essential amino acids was super strong and it is subject to a simple formula of two-term trend containing exponential and biotechnical laws. The absence of the second term determines the neutral type of behavior, and signs in the presence of the second member characterize the positive $(+)$ or negative (-) type of behavior of amino acids in the studied system of products. To identify the effect of oscillatory adaptation of essential amino acids to each other in some sets of products need more accurate (with measurement error, less than an order of magnitude) data.

\section{References}

1. Darwin Ch (1991) Origin of species by natural selection. Nauka, Leningrad, Russia, pp. 539.

2. Lavrenko EM (1959) Basic laws of plant communities and ways of their study Field geobotany. Publishing house of USSR Academy of Sciences, Moscow Leningrad, Russia 1: 7-263.

3. Chizhevsky AL (1924) Physical factors of historical process. Kaluga, Russia, p. 72.
4. Mazurkin PM (2006) Geoecology: Patterns of modern science. YoshkarOla: Mar GTU pp. 336.

5. Uemov AI (1963) Things, properties and relations. USSR Academy of Sciences Publishing, Moscow, Russia, pp.184.

6. Mazurkin PM (2013) Correlation variation. PGTU, Yoshkar-Ola, Russia, p. 56.

7. Dokuchaev VV (1954) Selected works. Moscow: State publishing house of agricultural literature Pp. 680.

8. Human genome.

9. Mazurkin PM (2014) Solution of the $23^{\text {rd }}$ Hilbert problem Interdisciplinary research in the field of mathematical modeling and computer science. Materials of the $3^{\text {rd }}$ scientific and practical Internet conference, SIMJET, Ulyanovsk, Russia, pp. 269-277.

10. Mazurkin PM (2014) Method of identification. International Multidisciplinary Scientific GeoConference Surveying Geology and Mining Ecology Management, SGEM 1 (6): 427-434.

11. Mazurkin PM (2015) Invariants of the Hilbert Transform for 23-Hilbert Problem, Advances in Sciences and Humanities. 1(1): 1-12.

12. Mazurkin PM (2015) Wavelet Analysis Statistical Data. Advances in Sciences and Humanities 1(2): 30-44.

13. Mazurkin PM (2016) Economic and statistical modeling: a textbook with a stamp of UMO RAE. Volga GTU, Yoshkar-Ola, Russia, pp. 276.

14. Mazurkin PM (2014) Identification of wave behavior of genes. Materials of scientific-practical conference Mathematical modeling in the field of cell biology, biochemistry and Biophysics. TSU, Togliatti, India, p. 43-52.

15. Mazurkin PM (2014) Identification of the wave patterns of behavior International Multidisciplinary Scientific Geo Conference Surveying Geology and Mining Ecology Management, SGEM 1 (6): 373-380.
(C) This work is licensed under Creative

To Submit Your Article Click Here: Submit Article
DOI: $10.32474 / \mathrm{CTBB} .2018 .01 .000105$

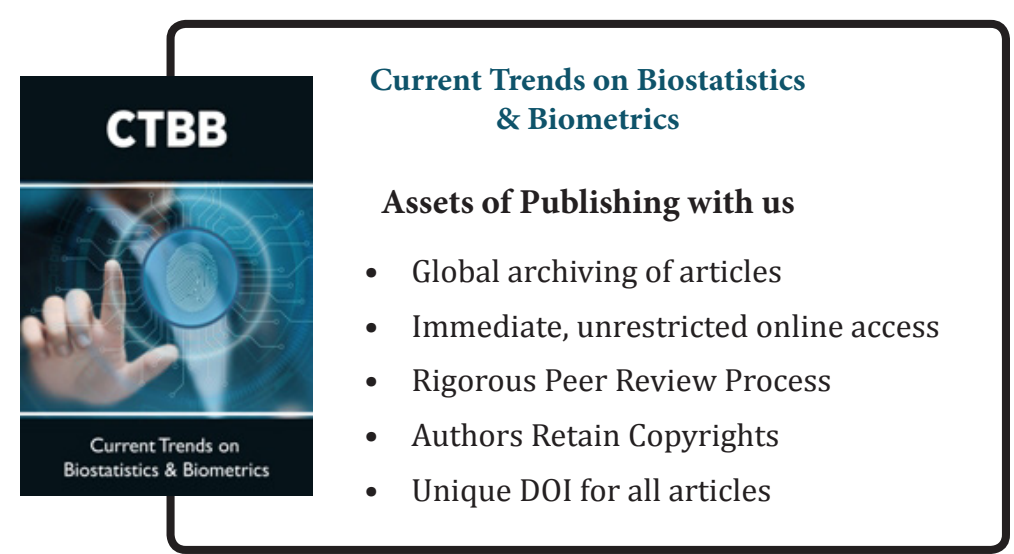

